\title{
Schoolwide Positive Behavioral Interventions and Support Practices: Review of Studies in the Journal of Positive Behavior Interventions"
}

\author{
Kürşat Ögülmüş ${ }^{1}$ \\ Kirıkkale University
}

\author{
Sezgin Vuran ${ }^{2}$ \\ Anadolu University
}

\begin{abstract}
Schoolwide Positive Behavioral Interventions and Support (SWPBIS) focuses on interventions in order to meet the social behavioral demands of schools with the help of a three-tiered model. The main aim in SWPBIS is to ensure behavioral success and academic achievement of students in schools. By analyzing the related studies it was seen that there are many studies focusing on the effectiveness of SWPBIS practices in schools and there is an ascending trend in the application of SWPBIS in schools. As a result, this study was conducted to review the experimental and quasi-experimental studies related to the SWPBIS published in the Journal of Positive Behavior Interventions (JPBI) between 1999 and 2015. The studies were examined in depth by using epistemological document analysis in 6 categorical areas: (a) purpose, (b) participants, (c) dependent variables, (d) method, (e) limitations, and (f) recommendations. Findings are discussed in accordance with the relevant literature. Finally, new proposals were made for new research and applicability in other countries.
\end{abstract}

Keywords

Schoolwide Positive Behavioral Interventions and Support (SWPBIS) • Positive Behavior Support (PBS) • Epistemological document analysis

\footnotetext{
* The authors would like to thank George SUGAI, Ph.D. and Aydın BAL, Ph.D. for their precious critical review and supports.

1 Correspondence to: Kürşat Ögülmüş, Special Education Specialist and Vice Director of Life Long Learning Research and Development Center, Kırıkkale University, Yahşihan, Kırıkkale, Turkey. Email: kursatogulmus@hotmail.com

2 Special Education Department, Faculty of Education, Anadolu University, Eskişehir, Turkey. Email: svuran@anadolu.edu.tr Citation: Öğülmüş, K., \& Vuran, S. (2016). Schoolwide positive behavioral interventions and support practices: Review of studies in the Journal of Positive Behavior Interventions. Educational Sciences: Theory \& Practice, 16, 1693-1710.
} 
Schools are valuable settings in that they provide children, families, educators, and community members with chances to learn, teach, and grow. These settings are able to present positive adult and peer examples, various and daily chances to have academic and social achievement, and permanent peer and adult relations promoted by social exchanges (Sugai et al., 2000).

Discipline problems such as widespread alcohol, drug abuse, and bullying shown in schools in the late 1990s, focused everyone's attention on these problem behaviors (Sugai \& Horner, 2002). Such problem behaviors increasing steadily in schools pushed people and policy makers to search for new solutions to prevent these problem behaviors in schools. As Skiba (2000) said, traditional methods such as zero tolerance, strict rules and punishment, and others were of no use. There was also no evidence-based research proving the positive effect of these methods on students. As Sugai and Horner noted, such systems not using positive behavior supports caused increases in the problem behaviors that needed to be reduced. In a similar way, Costenbader and Markson (1998) stated that exclusion and punishment of problem behaviors are not effective in the long term. Some types of punishment can even be rewarding and cause problem behaviors to continue. "Traditional school discipline practices" (TSDP) (Scheuermann \& Hall, 2011, pp. 12-13) and PBS (Positive Behavior Support) are compared in Table 1.

\begin{tabular}{ll}
\hline Table 1 & \\
Comparison of TSDP and PBS & \multicolumn{1}{c}{ TSDP } \\
\hline \multicolumn{2}{c}{ PBS } \\
\hline Preventing problem behaviors with zero tolerance, & $\cdot \begin{array}{l}\text { Preventing problem behaviors with positive } \\
\text { strict rules, and punishment }\end{array}$ \\
$\cdot$ Quick and easy to apply & $\cdot$ Leng-time commitment and planning \\
$\cdot$ No evidence & $\cdot$ There are many evidence-based practices \\
$\cdot$ Data are not so important & $\cdot$ Data-based decision making \\
$\cdot$ Functions of behavior are not important & $\cdot$ Functions of behavior are very important \\
$\cdot$ Focus on inappropriate behavior & $\cdot$ Focus on positive behavior \\
$\cdot$ Intervention is applied after problem behavior & $\cdot$ Prevention of inappropriate behavior is targeted \\
occurred (Consequence based) & (Antecedent based) \\
$\cdot$ Less preferred & $\cdot$ Steadily increasing usage in schools \\
$\cdot$ Not based on team & $\cdot$ Team-based \\
\hline
\end{tabular}

Sprague and Horner (2006) indicated the main points of a schoolwide system for positive behavior support are: (a) problem behavior in schools is not only an important social challenge but also an obstacle to effective learning; (b) it has not been proven that conventional "get tough" approaches are effective; (c) a positive social culture needs to be established first through describing, teaching, and rewarding appropriate behaviors as the basis for all behavior support; (d) further behavior support processes beased on principles of behavior analysis are essential for students who need greater behavior support; (e) school staff are able not only to gather and utilize quality enhancement data systems, but also appreciate the value of those systems in terms of enhancing schools (pp. 413-427). 
PBS is neither a recent intervention package nor a recent behavior theory; it is rather a practice of a systems approach based on behavior to improve the capacity of schools, families, and communities with the aim of building effective settings that enhance the harmony or connection among practices validated by research and the settings where teaching and learning happen. It is focused on building and maintaining school settings that enhance behavioral outcomes for all children and youth through decreasing the effectiveness, efficiency, and relevance of problem behavior and increasing the functionality of desired behavior (Sugai et al., 2000).

\section{SWPBIS Framework}

SWPBIS is defined by the processes arranged around three major themes: Prevention, Multi-Tiered Support, and Data-based Decision Making. Contributing to the prevention of problem behavior are these principles: (a) describing and teaching basic behavioral expectations; (b) approving and awarding appropriate behavior (e.g., obeying the rules of the school, secure and considerate peer relations, and academic work/involvement); and (c) building a regular continuation of outcomes for problem behavior. Attention is focused on building a positive social atmosphere where expectations of behavior for students are greatly foreseeable, directly taught, constantly approved, and actively observed (Sprague \& Horner, 2006).

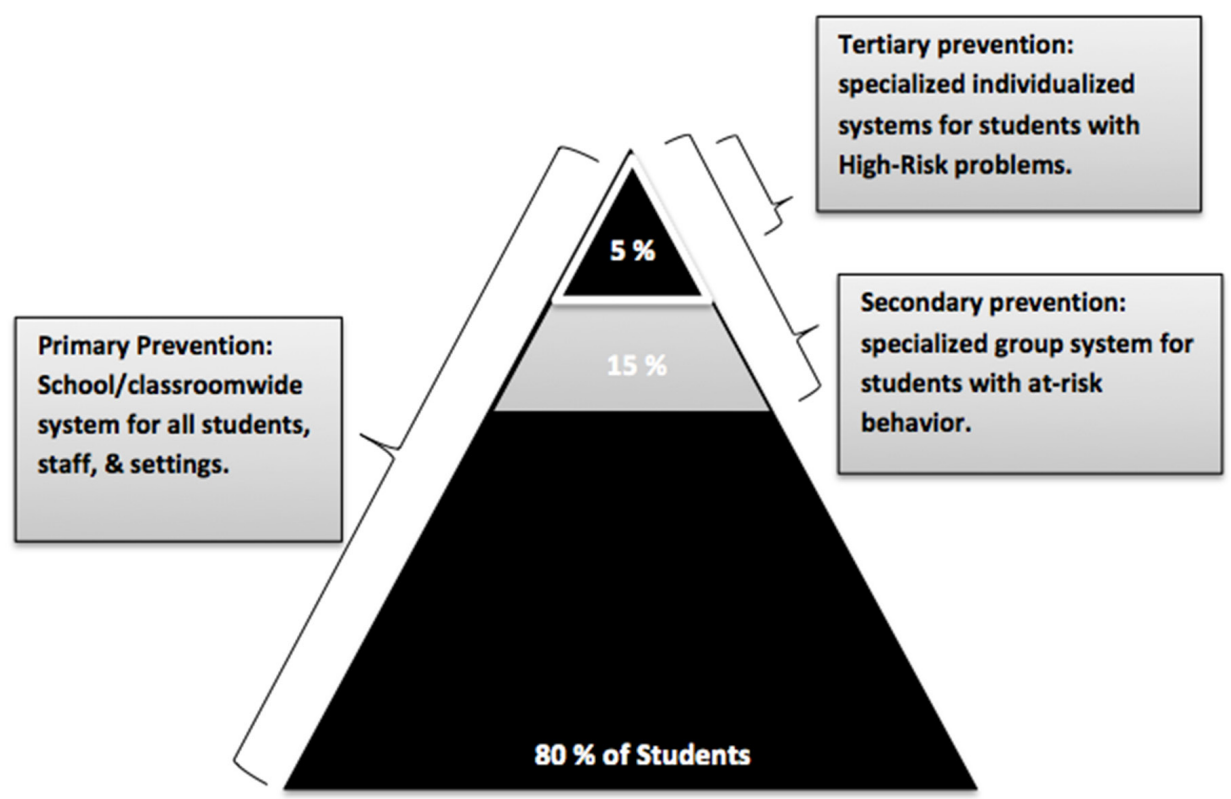

Source: http://www.icareby.org/sites/default/files/spr352sugai.pdf

Figure 1. Three-tiered prevention continuum of positive behavior support (Sugai \& Horner, 2006). 
Horner, Todd, Lewis-Palmer, Irvin, Sugai, and Boland (2004) explained the Seven Key Features of Schoolwide Positive Behavior Support as: (a) describe 3-5 expectations for appropriate behavior schoolwide; (b) actively have all students learn the schoolwide expectations of behavior; (c) observe and approve of students when they engage in expectations of behavior; (d) correct problem behaviors by using a continuation of behavioral outcomes regularly administrated; (e) collect and use data about student behavior in order to assess and direct decision-making; (f) get leadership of schoolwide applications from a director who 1. organizes a team to establish, carry out, and administer the schoolwide behavior support attempt in a school; 2. works as a team member; 3 . assigns enough time to carry out behavior support processes; and 4. places schoolwide behavior among the most important three enhancement objectives for the school; (g) get district-level support in the form of 1. education in schoolwide behavior support applications, 2. procedures that focus on the expectations that schools are secure and arranged for effective learning, and 3. expectation that data about problem behavior models be collected and reported.

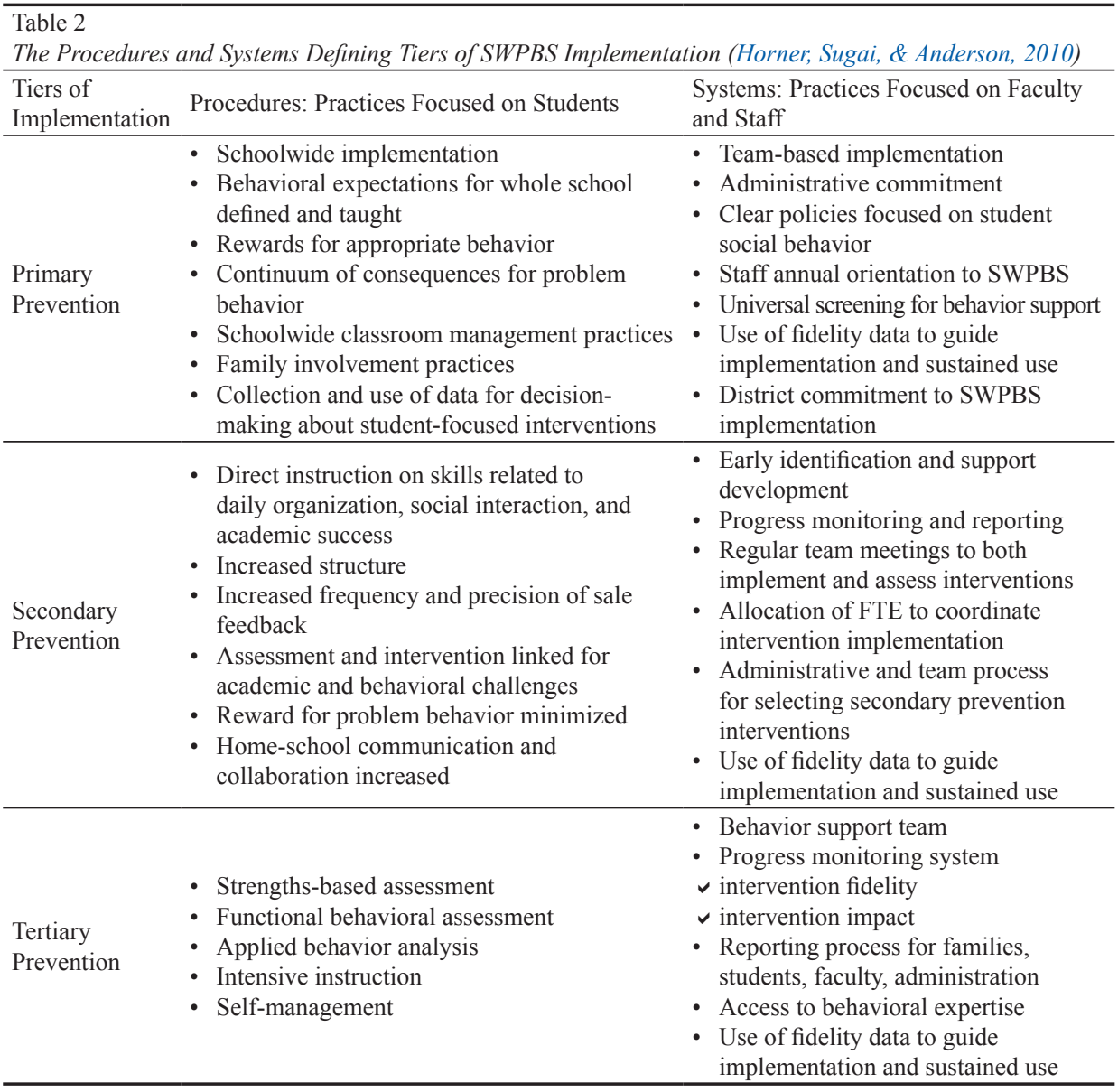

Source: http://www.dropoutprevention.org/sites/default/files/horner_sugai_anderson_2010_evidence.pdf 
PBS has been used as an approach that allows schools to describe and activate these systems and processes in the last several years. PBS has been among the notable policies and applications in state schools in the last 7 years (Walker, Cheney, Stage, Blum, \& Horner, 2005). Over 4,000 schools in the United States are now applying SWPBIS, and it is expected that the number of these schools will increase by $100 \%$ in the near future (U.S. Dept. of Education, 2005). According to the report of the Technical Assistance Center on Positive Behavioral Interventions and Supports (U.S. Dept. of Education, 2005), almost 5,000 schools in 40 states have embraced an approach in order to positively and proactively deal with how all students in a school behave where SWPBS is used, and it is defined as "a wide range of fundamental and specified processes that aim to achieve significant social and academic consequences besides impeding problem behavior with all of the students" (Sugai et al., 2010). Different stages of embracing SWPBIS are now seen in at least 7,000 schools in the United States (Bradley, Doolittle, Lopez, Smith, \& Sugai, 2007). In total, SWPBIS has been adopted by 7,953 schools. Overall, 47 states claim that they are at some level of application (Spaulding, Horner, May, \& Vincent, 2008).

More than 9,000 U.S. schools are now implementing SWPBIS in order to decrease disruptive behavior problems by applying the principles of behavior, social learning, and organizational behavior (Bradshaw, Mitchell, \& Leaf, 2010). It is known that at least 13,000 schools in the US and Canada are now applying SWPBIS (Center on Positive Behavioral Interventions and Supports, 2010), and over 14,000 schools across the US have been educated in SWPBIS known to not only decrease behavior problems but also to foster a positive school atmosphere (Debnam, Pas, \& Bradshaw, 2012).

Although the number of schools applying SWPBIS is increasing each year, Sugai et al. (2000) especially emphasized some important components of SWPBIS such as the description, embracement, and maintained use of procedures, systems, data-based decision making, and processes for successful applications in schools.

New journals such as JPBI, technical assistance centers such as PBIS, and staff preparation programs have employed PBS as the main point of their aims and activities. The aim of this study is to analyze the studies addressing SWPBIS practices in the single international level academic journal related to PBS which is named JPBI and published since 1999. The findings are discussed taking into consideration the related literature. After discussing, "How can 'SWPBIS' be applied in other countries? and What kind of regulations are needed?" some practical advice and recommendations are developed.

\section{Method}

As this research investigates articles thematically published in JPBI related to PBS practices in schools, the model for this research is "descriptive." JPBI mainly offers 
research-based articles about positive behavior support to use in school, home, and social environments. Among typical elements are experimental research; argument, literature reviews, theoretical articles; programs, applications, and novelties; forum, and media checks.

According to the investigation conducted by Thomson Reuters (2015), the impact factor of this journal is 1.409 and the rates of Ranking by the year 2014 is 76/119 in Clinical Psychology and 15/39 in Special Education. This journal is preferred for being the single journal related to PBS applications. Epistemological document analysis was used as the data collection method in this research. In the first stage of the document analysis, studies identified as being in the sample group were downloaded from the JPBI website and classified according to publication years. In the second stage, all studies were reviewed and classified according to topics. Between the years 1999-2014, a total of 61 studies were identified as related to the PBS; 31 of these studies are related to family-centered PBS, seven are related to the functional behavior analysis, six are related to class- wide PBS, and 17 are related to SWPBIS. In the third stage, 17 studies whose independent variable was SWPBIS were examined in depth in six categorical areas: (a) purpose, (b) participants, (c) dependent variables, (d) methods, (e) limitations, and (f) recommendations. The findings were tabulated. After the first researcher examined each of the articles indepth, an audit trail was made until all of the articles in this study were analyzed by the authors. In this process, the information on the table was read together and if new information was required, it was added to the table. Researchers create an audit trail by recording the research practice through journaling and memoiring, having an inquiry record of all practices, creating a data collection history, and documenting data analysis processes openly. This record is then analyzed by an outside evaluator considering these questions: Are the findings data based? Do inferences use reason? Is the grouping format relevant? Are the research decisions and procedural changes justifiable? How prejudiced is the researcher? What methods were used to promote reliability (Schwandt \& Halpern, 1988)? The chronological record is deemed reliable as a result of this work of documenting research and an examination of the documentation by an outside evaluator.

\section{Findings}

In this section 17 studies whose independent variable was SWPBIS were examined in depth within six categorical areas and the findings were tabulated. Additionally, results of in-depth investigation by using content analysis of (a) dependent variables, (b) settings of the studies, (c) school types, (d) methods, and (e) suggestions made in the studies are presented in a systematic way in the following tables. 


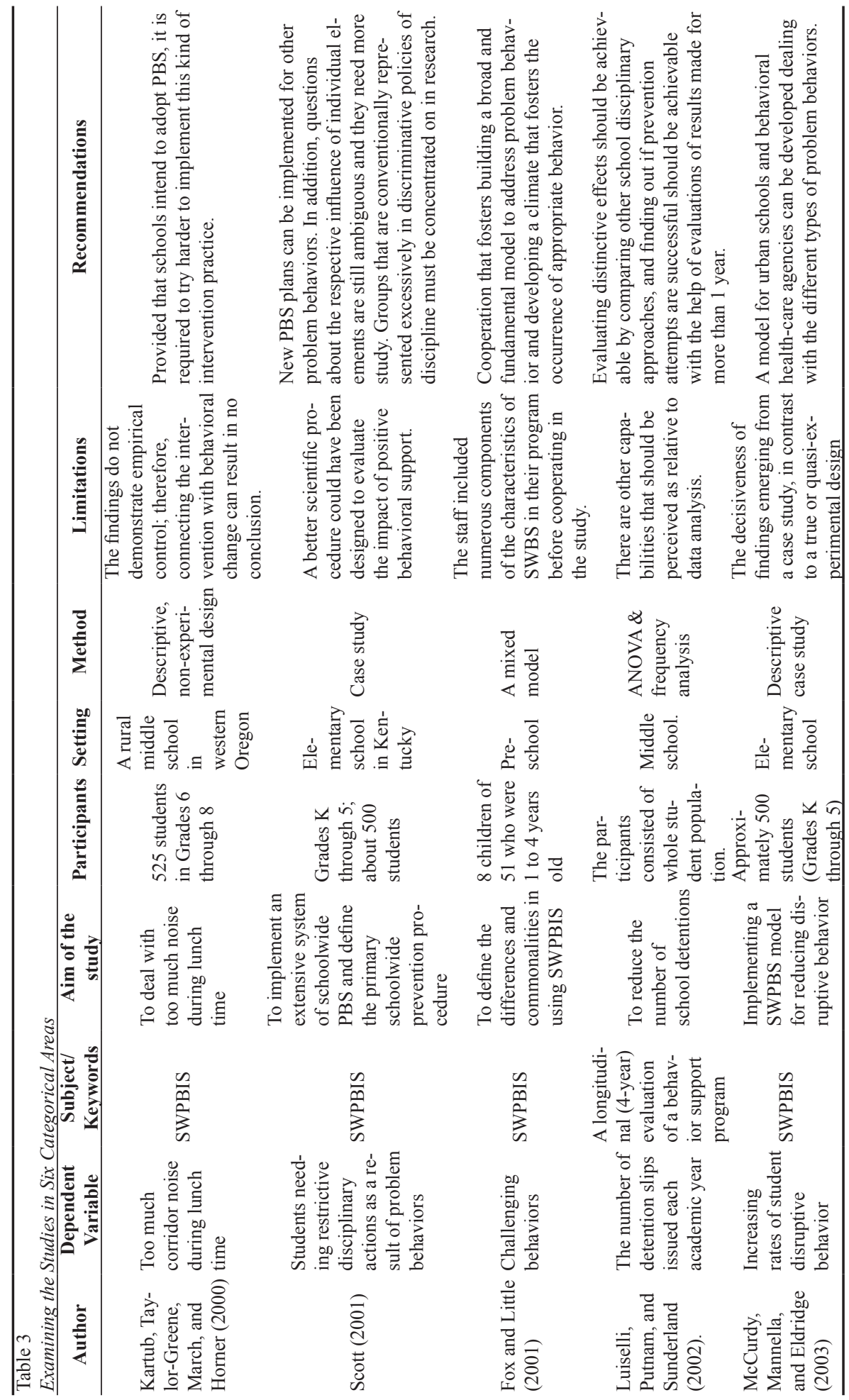




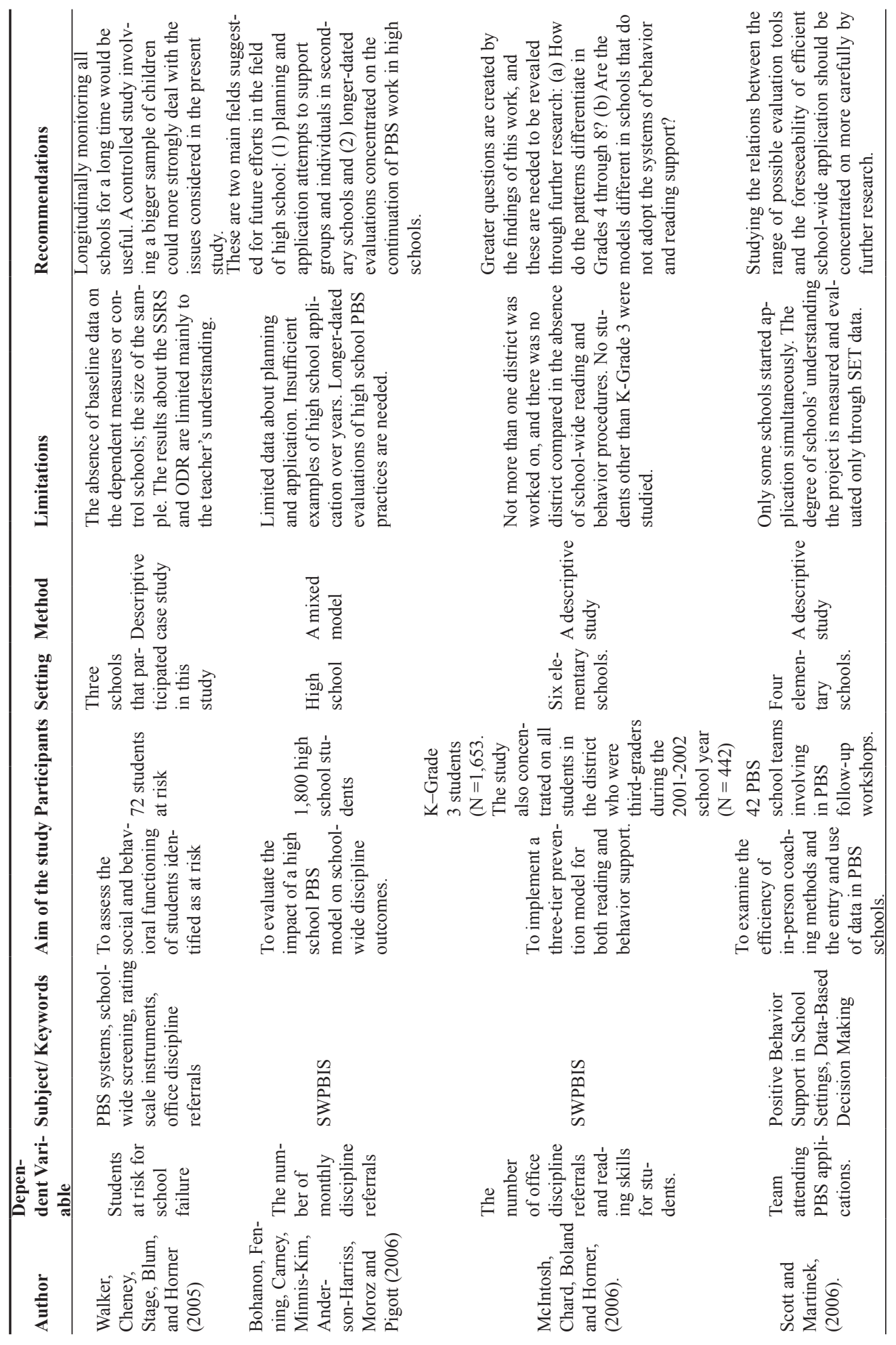




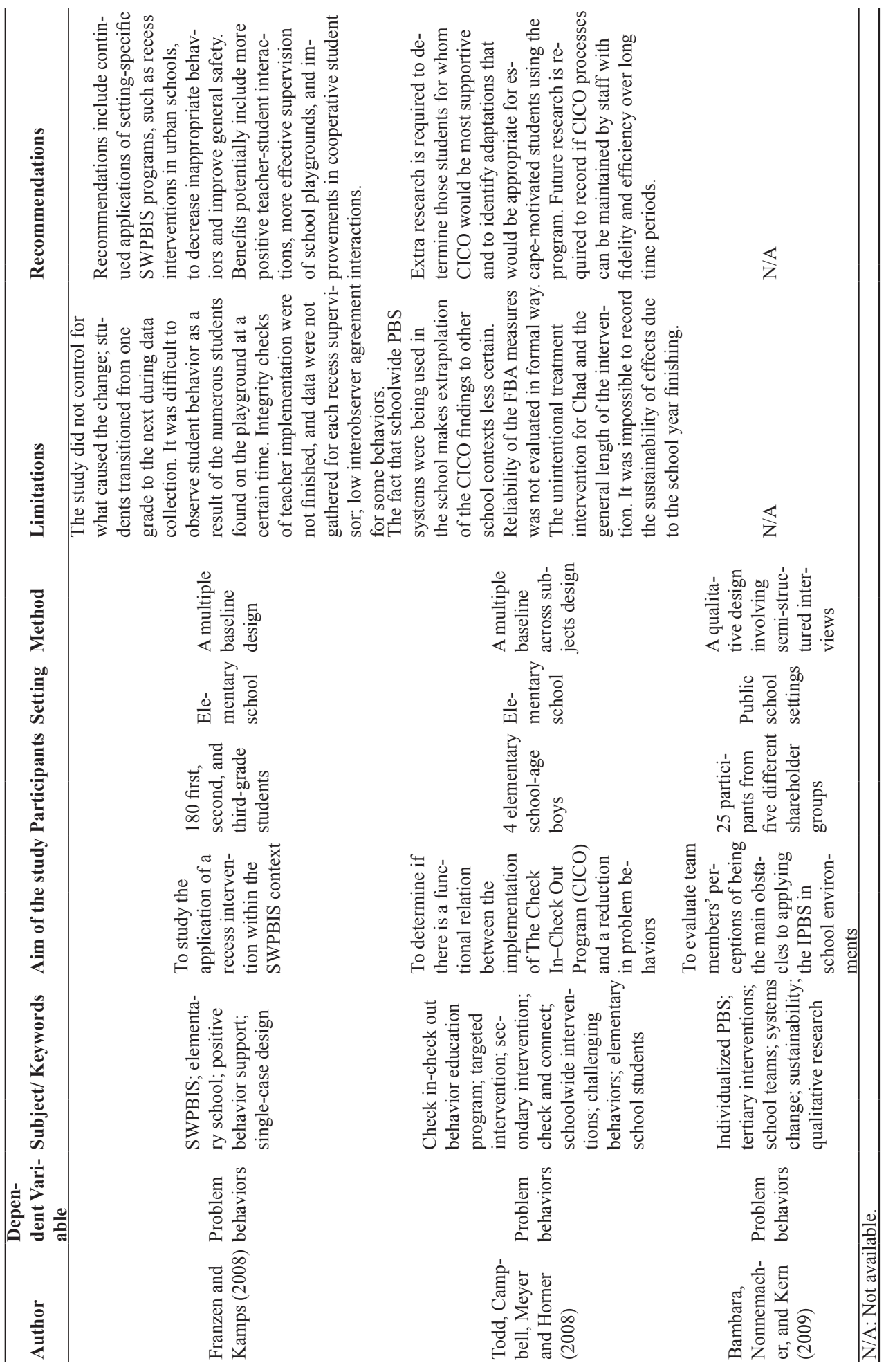




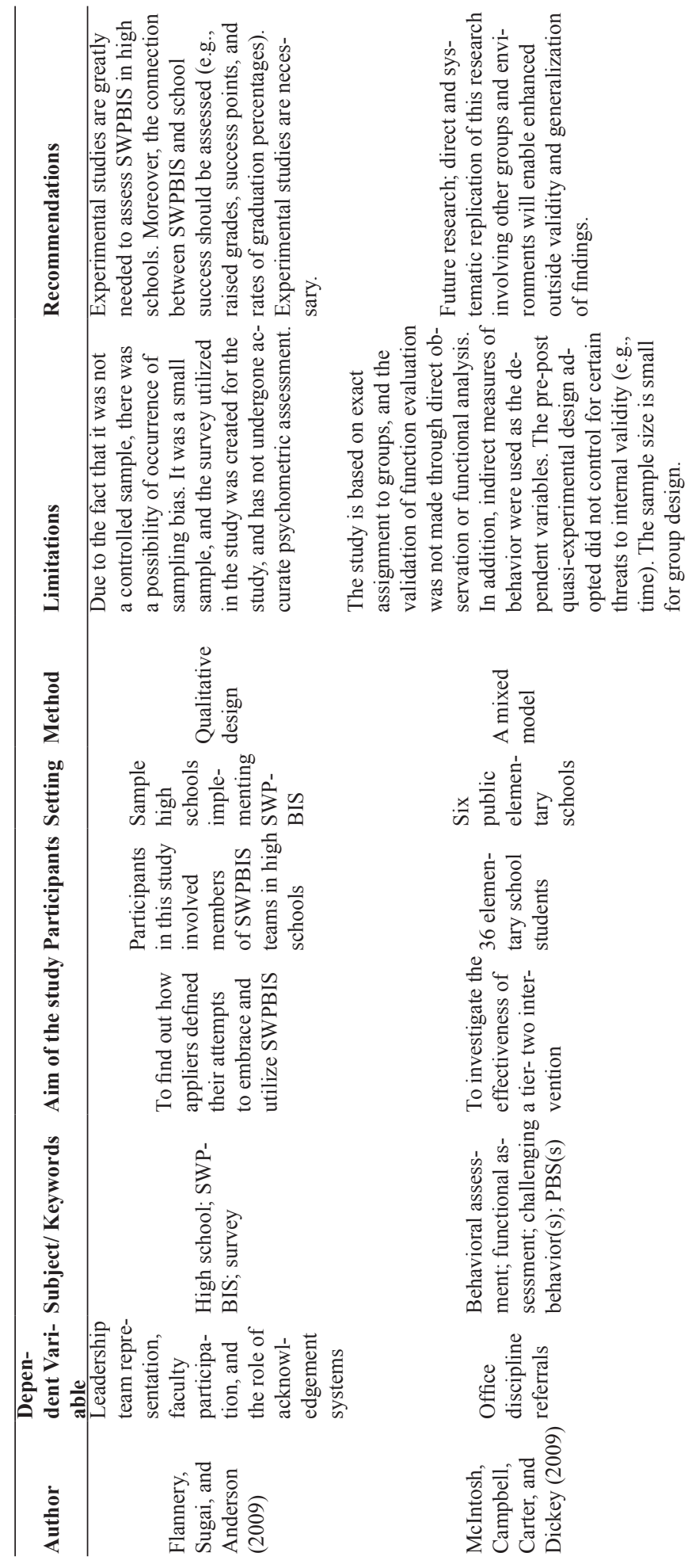


节
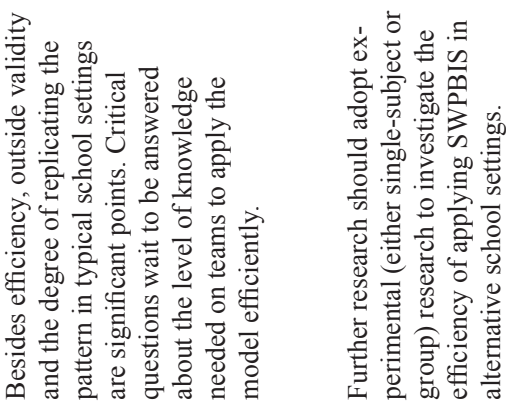

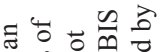

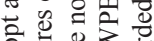

을

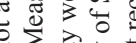

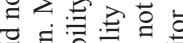

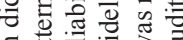

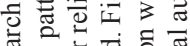

ङ

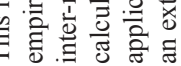

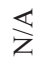

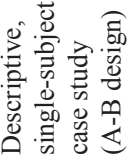

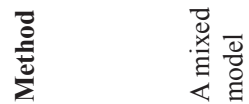

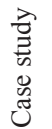

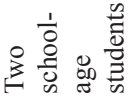

之.

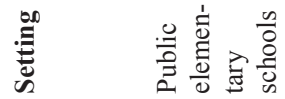

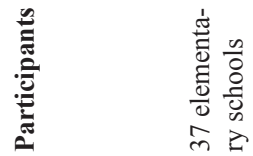

है $m$

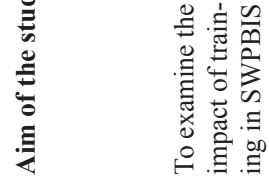

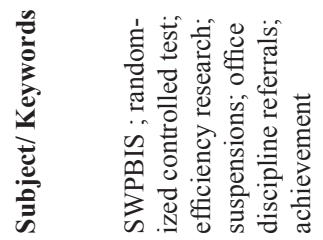

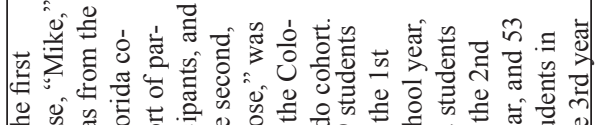

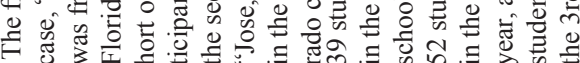

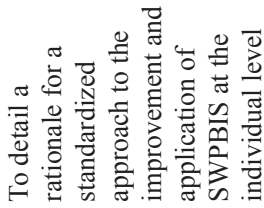
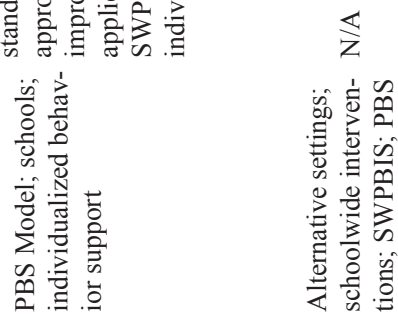

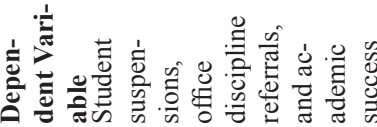
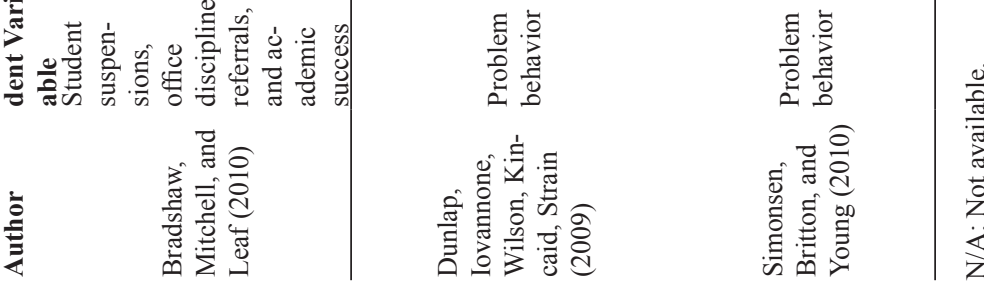
Table 4

Classifying the Dependent Variables of the Studies

\begin{tabular}{lll}
\hline Dependent Variable & Author & $f \%$ \\
\hline
\end{tabular}

(Kartub, Taylor-Greene, March, and Horner, 2000; Scott, 2001; Fox and Little, 2001; Luiselli, Putnam, and Sunderland, 2002; McCurdy, Mannella, and Eldridge,

1. Managing prob- 2003; Bohanon, Fenning, Carney, Minnis-Kim, Anderson-Harriss, Moroz, and lem behaviors Pigott, 2006; Franzen and Kamps, 2008; Todd, Campbell, Meyer, and Horner, 2008; McIntosh, Campbell, Carter, and Dickey, 2009; Dunlap, Iovannone, Wilson, Kincaid, and Strain, 2009; Simonsen, Britton, and Young, 2010)

2. Evaluation of (Scott and Martinek, 2006; Bambara, Nonnemacher, and Kern, 2009; Flanthe team nery, Sugai, and Anderson, 2009)

3. Academic failure and problem behaviors

(Macintosh, Chard, Boland, and Horner, 2006; Bradshaw, Mitchell, and Leaf, 212 2010)

4. Academic failure (Walker, Cheney, Stage, Blum, and Horner, 2005)

When the studies were classified according to their dependent variables it was seen that most of them were composed of "managing problem behaviors." The second group of dependent variables is "evaluation of the team." The other group of dependent variables is "both for academic failure and problem behaviors." And the last dependent variable is "academic failure."

\begin{tabular}{llrr}
\hline $\begin{array}{l}\text { Table } 5 \\
\text { Classifying the Settings of the Studies }\end{array}$ & \multicolumn{1}{c}{ Author } & $f$ & $\%$ \\
\hline Setting & \multicolumn{1}{c}{\begin{tabular}{l}
\multicolumn{1}{c}{ (Kartub, Taylor-Greene, March, and Horner, 2000; Todd, Campbell, Meyer, and Horner, } \\
2008; Bradshaw, Mitchell, and Leaf, 2010)
\end{tabular}} & 24 \\
\hline $\begin{array}{l}\text { 1. Rural } \\
\text { (Scott, 2001; McCurdy, Mannella, and Eldridge, 2003; Bohanon et al., 2006; Franzen and } \\
\text { Kamps, 2008; Flannery, Sugai, and Anderson, 2009) }\end{array}$ & 5 & 24 \\
\hline
\end{tabular}

As we classified the studies according to settings in Table 5, the diversity of the studies according to settings is not so variable. The setting in seven studies cannot be determined. In some studies, the setting was "rural" and in others the setting was "urban."

Table 6

Classifying the School Types Involved in the Studies

\begin{tabular}{|c|c|c|c|}
\hline School & Author & $f$ & $\%$ \\
\hline $\begin{array}{l}\text { 1. Elementary } \\
\text { School }\end{array}$ & $\begin{array}{l}\text { (Simonsen, Britton, and Young, 2010; Franzen and Kamps, 2008; Todd, Camp- } \\
\text { bell, Meyer, and Horner, 2008; Macintosh, Chard, Boland, and Horner, 2006; Scott, } \\
\text { 2001; McCurdy, Mannella, and Eldridge, 2003; Scott and Martinek, 2006) }\end{array}$ & 7 & 41 \\
\hline $\begin{array}{l}\text { 2. High } \\
\text { School }\end{array}$ & $\begin{array}{l}\text { (Bohanon, Fenning, Carney, Minnis-Kim, Anderson-Harriss, Moroz, and Pigott, } \\
\text { 2006; Fenning et al., 2006; Flannery, Sugai, and Anderson, 2009) }\end{array}$ & 3 & 18 \\
\hline $\begin{array}{l}\text { 3. Middle } \\
\text { School }\end{array}$ & $\begin{array}{l}\text { (Kartub, Taylor-Greene, March, and Horner, 2000; Luiselli, Putnam, and Sunder- } \\
\text { land, 2002) }\end{array}$ & 2 & 12 \\
\hline 4. Pre-School & (Fox and Little, 2001; Bradshaw, Mitchell, and Leaf, 2010) & 2 & 12 \\
\hline
\end{tabular}

As seen in Table 6, most of the studies were conducted in elementary schools. In order of numbers per school type, the second one is High School, the third one is Middle School, and the last one is Pre-School. 


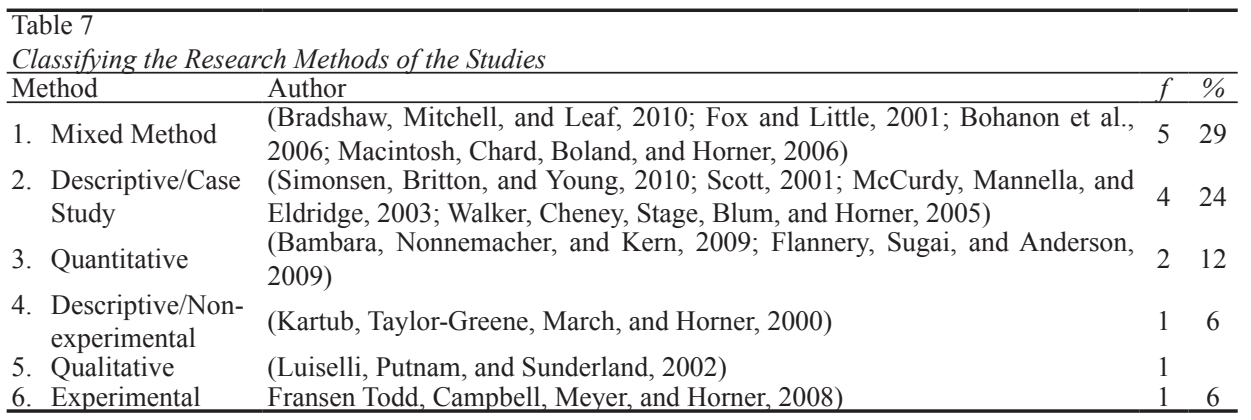

As seen in the Table 7, in most of the studies descriptive/case study and mixed methodology were preferred by the authors. Descriptive, descriptive/nonexperimental, qualitative, quantitative, and experimental methods are among the other methods used in these studies.

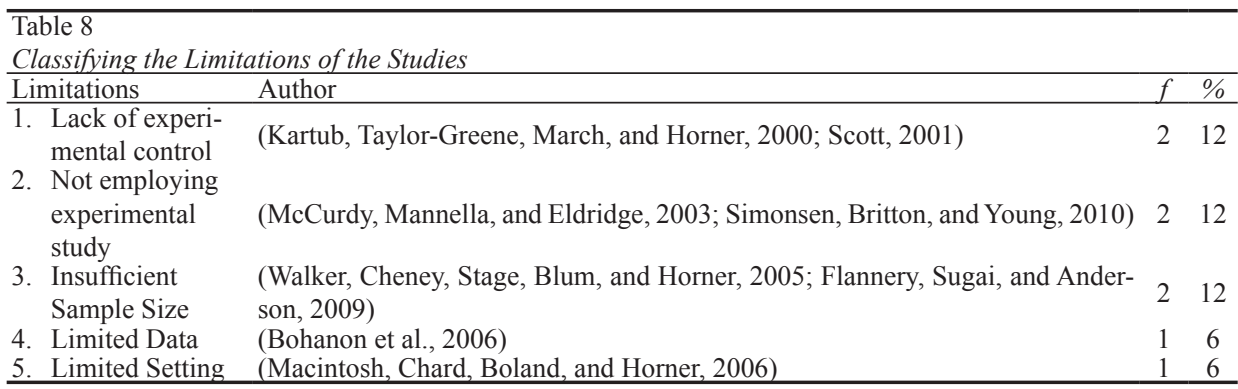

When the limitations were classified as in Table 8 it was seen that some common ones stood out, such as: lack of experimental control, not employing experimental study, insufficient sample size, limited data, and limited setting.

Table 9

Classifying the Suggestions of the Studies

Suggestions

lem behaviors in other schools

2. More efforts should be made in applying SWPBIS in schools

3. Alternative PBS plans should be implemented for other problem behaviors

4. Comparative studies should employ alternative models

5. Longitudinal study should be conducted

6. Future studies focusing on evaluation instruments should be conducted

7. Future studies focusing on empirical studies should be conducted

8. Replication of the studies with different participants

\begin{tabular}{lcc} 
Author & $f$ & $\%$ \\
\hline (Fox and Little, 2001; McCurdy, Mannella, and & 2 & \\
& &
\end{tabular}

Eldridge, 2003)

(Kartub, Taylor-Greene, March, and Horner, 2000).

(Scott, 2001)

16

(Luiselli, Putnam, and Sunderland, 2002)

(Walker, Cheney, Stage, Blum, and Horner, 2005)

(Scott and Martinek, 2006)

(Flannery, Sugai, and Anderson, 2009)

(Macintosh, Chard, Boland, and Horner, 2006)

9. Future studies focusing on experimental stud- (Simonsen, Britton, and Young, 2010) ies should be conducted

\section{2} 2 2 6 
The suggestions made in the studies gathered and shown in Table 9 are very important for future studies.

\section{Discussion}

As seen in the findings of this study, the dependent variables in most of the studies were targeted for managing the problem behaviors in rural or urban elementary schools. Based on this we can say that educators and psychologists are mostly concerned about "problem behavior" in schools. When we reviewed the other sources in this study and outside the scope of this research we saw that effective evidence- based interventions and practices have been documented for addressing problem behaviors (Bohanon et al., 2006; Dunlap, Iovannone, Wilson, Kincaid, \& Strain, 2010; Fox \& Little, 2001; Franzen \& Kamps, 2008; Kartub, Taylor-Greene, March, \& Horner, 2000; Luiselli, Putnam, \& Sunderland, 2002; McCurdy, Mannella, \& Eldridge, 2003; McIntosh, Campbell, Carter, \& Dickey, 2009; Scott, 2001; Simonsen, Britton, \& Young, 2010; Todd, Campbell, Meyer, \& Horner, 2008). Nevertheless, maintained and extended uses of these interventions and implementations have not been regular or extensive in other countries except the USA. The use of SWPBIS has an ascending trend day by day in schools, especially in the USA.

There are many studies showing the effectiveness of SWPBIS. This is one of the most important reasons for this method becoming widespread in schools (Anderson \& Kincaid, 2005). The principles and technology of behavior analysis have been proved to be highly efficient for decreasing problem behavior and increasing students' social skills. These principles and techniques have lately been implemented schoolwide.

As seen in the studies above related to SWPBIS, the overall picture is encouraging. There are many evidence-based studies (Dunlap et al., 2010; Fox \& Little, 2001; Kartub et al., 2000; Luiselli et al., 2002; McCurdy et al., 2003; McIntosh et al., 2009; Scott, 2001; Simonsen et al., 2010; Todd et al., 2008) showing the feasibility of this approach.

As the number of schools implementing SWPBIS increases, more schools are making efforts toward the implementation of this approach for both academic success and problem behaviors. As Sprague and Horner (2006) said, schools can enhance and show that change is related to valuable student consequences with the help of SWPBIS.

Beyond these there are some limitations as mentioned in the studies above such as "lack of experimental control," "not employing experimental study," "insufficient sample size," "limited data and limited setting." As SWPBIS has been applied in schools with great numbers of participants the chance of experimental control and employing experimental study is limited (Kartub et al., 2000; McCurdy et al., 2003; Scott, 2001; Simonsen et al., 2010). According to Sugai and Horner 
(2006), the effects of SWPBIS are promising but some children do not respond sufficiently to the global model so new, more applicable SWPBIS plans should be implemented by researchers. Horner et al. (2010) mentioned in a similar way that as the field of education starts using evidence-based processes, consistent arguments will be appropriate in favor of standards for determining whether data supports an intervention's efficiency. Nevertheless, more research is necessary for better measuring the extent, communication effects with efficient intervention, and continuation of SWPBIS practice and results. Generally, the data have been obtained by using mixed methods (Bohanon et al., 2006; Bradshaw et al., 2010; Fox \& Little, 2001; McIntosh, Chard, Boland, \& Horner, 2006).

As Bradshaw, Koth, Thornton, and Leaf (2009) mentioned, even though policymakers, researchers, and educators are increasingly interested in schoolwide PBIS, comparatively little organized research utilizing randomized controlled test patterns has been conducted on the influence of PBIS. They reviewed how PBIS influenced staff reports that school administrative health prepared utilizing information from a group-randomized controlled efficiency test of PBIS and they demonstrated a noteworthy impact of PBIS on general administrative health, source effect, staff relationship, and academic prominence.

In another randomized controlled trials study conducted by Bradshaw, Waasdorp, and Leaf (2012) it was suggested that there are direct effects of SWPBIS on a variety of behavior problems, such as ODRs (Office Discipline Referrals), focusing challenges, aggressive or disruptive behavior, and enhancements in prosocial behaviors and feeling management. Prosocial behavior and feeling management have comparatively unique effects on PBIS in the literature.

Research conducted by Waasdorp, Bradshaw, and Leaf (2012) pointed out that students in schools where SWPBIS was applied exhibited less bullying and peer refusal according to teachers' reports than students in schools where SWPBIS was not implemented. Moreover, a notable relation appeared between grade level of early exposure to SWPBIS and intervention quality, and it indicated that children first exposed to SWPBIS earlier experienced the strongest impacts of SWPBIS on peer refusal patterns.

There were some limitations to our study. We did not try to present an extensive review of the literature on SWPBIS. Our aim was to identify the research that focused directly on the question of SWPBIS implementation and efficiency in the single international-level academic journal related to PBS (i.e., JPBI published since 1999). Other research in other journals can be dealt with in future studies. In this study we tried to gather important applicable sample studies so that SWPBIS models and applications can be adopted for future use for the problem behaviors. 
In conclusion, SWPBIS has had a significant effect on improving school climate by attributing to it students' social competence and academic achievement. Although this method has been applied in many schools and supported with empirical studies, there are no applications in some countries. This method also can be implemented in other countries to minimize problem behaviors and raise academic achievement levels. The schools appropriate to apply this method can use SWPBIS for problem behaviors and academic failure. Limitations defined in this study are very important for the sake of future researchers dealing with them. The authors working on this study will increase SWPBIS applicability in their countries. By considering this study, practitioners in other countries may carry out the replication of the identified studies with different student participants in search of new models. Also, academicians working in related fields can conduct future studies focusing on experimental studies in cooperation with schools willing to adopt this method.

\section{References}

Anderson, C. M., \& Kincaid, D. (2005). Applying behavior analysis to school violence and discipline problems: Schoolwide positive behavior support. The Behavior Analyst, 28(1), 49.

Bambara, L. M., Nonnemacher, S., \& Kern, L. (2009). Sustaining school-based individualized positive behavior support: Perceived barriers and enablers. Journal of Positive Behavior Interventions, 11(3), 161-176.

Bohanon, H., Fenning, P., Carney, K. L., Minnis-Kim, M. J., Anderson-Harriss, S., Moroz, K. B., ... \& Pigott, T. D. (2006). Schoolwide application of positive behavior support in an urban high school: A case study. Journal of Positive Behavior Interventions, 8(3), 131-145.

Bradley, R., Doolittle, J., Lopez, F., Smith, J., \& Sugai, G. (2007, January 30). Discipline: Improved understanding and implementation. OSEP Part B Regulations Regional Implementation Meeting: Building the Legacy IDEA 2004, Washington, DC.

Bradshaw, C. P., Koth, C. W., Thornton, L. A., \& Leaf, P. J. (2009). Altering school climate through school-wide positive behavioral interventions and supports: Findings from a group-randomized effectiveness trial. Prevention Science, 10(2), 100-115.

Bradshaw, C. P., Mitchell, M. M., \& Leaf, P. J. (2010). Examining the effects of schoolwide positive behavioral interventions and supports on student outcomes results from a randomized controlled effectiveness trial in elementary schools. Journal of Positive Behavior Interventions, 12(3), 133-148.

Bradshaw, C. P., Waasdorp, T. E., \& Leaf, P. J. (2012). Effects of school-wide positive behavioral interventions and supports on child behavior problems. Pediatrics, 130(5), 1136-1145.

Center on Positive Behavioral Interventions and Supports. (2010). Schools that are implementing SWPBIS. Retrieved from www.pbis.org

Costenbader, V., \& Markson, S. (1998). School suspension: A study with secondary school students. Journal of School Psychology, 36(1), 59-82.

Debnam, K. J., Pas, E. T., \& Bradshaw, C. P. (2012). Secondary and tertiary support systems in schools implementing school-wide positive behavioral interventions and supports: A preliminary descriptive analysis. Journal of Positive Behavior Interventions 14(3), 142-152. 
Dunlap, G., Iovannone, R., Wilson, K. J., Kincaid, D. K., \& Strain, P. (2010). Prevent-TeachReinforce: A standardized model of school-based behavioral intervention. Journal of Positive Behavior Interventions, 12(1), 9-22. http://dx.doi.org/10.1177/1098300708330880

Flannery, K. B., Sugai, G., \& Anderson, C. M. (2009). School-wide positive behavior support in high school early lessons learned. Journal of Positive Behavior Interventions, 11(3), 177-185.

Fox, L., \& Little, N. (2001). Starting early developing school-wide behavior support in a community preschool. Journal of Positive Behavior Interventions, 3(4), 251-254.

Franzen, K., \& Kamps, D. (2008). The utilization and effects of positive behavior support strategies on an urban school playground. Journal of Positive Behavior Interventions, 10(3), 150-161.

Horner, R. H., Sugai, G., \& Anderson, C. M. (2010). Examining the evidence base for schoolwide positive behavior support. Focus on Exceptional Children, 42(8), 1-14.

Horner, R. H., Todd, A. W., Lewis-Palmer, T., Irvin, L. K., Sugai, G., \& Boland, J. B. (2004). The School-Wide Evaluation Tool (SET): A research instrument for assessing school-wide positive behavior support. Journal of Positive Behavior Interventions, 6(1), 3-12.

Kartub, D. T., Taylor-Greene, S., March, R. E., \& Horner, R. H. (2000). Reducing hallway noise: A systems approach. Journal of Positive Behavior Interventions, 2(3), 179-182.

Luiselli, J. K., Putnam, R. F., \& Sunderland, M. (2002). Longitudinal evaluation of behavior support intervention in a public middle school. Journal of Positive Behavior Interventions, 4(3), 184-190.

McCurdy, B. L., Mannella, M. C., \& Eldridge, N. (2003). Positive behavior support in urban schools: Can we prevent the escalation of antisocial behavior? Journal of Positive Behavior Interventions, 5(3), 158-170.

McIntosh, K., Campbell, A. L., Carter, D. R., \& Dickey, C. R. (2009). Differential effects of a tier two behavior intervention based on function of problem behavior. Journal of Positive Behavior Interventions, 11(2), 82-93.

McIntosh, K., Chard, D. J., Boland, J. B., \& Horner, R. H. (2006). Demonstration of combined efforts in school-wide academic and behavioral systems and incidence of reading and behavior challenges in early elementary grades. Journal of Positive Behavior Interventions, 8(3), 146-154.

Thomson Reuters. (2015). 2014 Journal Citation Reports ${ }^{\circledR}$ Social Sciences Edition. Retrieved from http://ipscience.thomsonreuters.com/product/journal-citation-reports/?utm_source=false\&utm_medium=false\&utm_campaign=false

Scheuermann, B. K., \& Hall, J. A. (2011). Positive behavioral supports for the classroom. New York, NY: Pearson Higher Education.

Schwandt, T. A., \& Halpern, E. S. (1988). Linking auditing and meta-evaluation: Enhancing quality in applied research. Thousand Oaks, CA: Sage.

Scott, T. M. (2001). A schoolwide example of positive behavioral support. Journal of Positive Behavior Interventions, 3(2), 88-94.

Scott, T. M., \& Martinek, G. (2006). Coaching positive behavior support in school settings: Tactics and data-based decision making. Journal of Positive Behavior Interventions, 8(3), 165-173.

Simonsen, B., Britton, L., \& Young, D. (2010). School-wide positive behavior support in an alternative school setting: A case study. Journal of Positive Behavior Interventions, 12(3), 180-191.

Skiba, R. J. (2000). Zero tolerance, zero evidence: An analysis of school disciplinary practice (Policy Res. Rep. No. RR-SRS2). Bloomington, IN: Indiana University, Education Policy Center, Smith Research Center. 
Spaulding, S. A., Horner, R. H., May, S. L., \& Vincent, C. G. (2008). Implementation of school-wide PBIS across the United States. Eugene, OR: OSEP Technical Assistance Center on Positive Behavioral Interventions and Supports.

Sprague, J. R., \& Horner, R. H. (2006). School wide positive behavioral supports. In S. R. Jimerson \& M. J. Furlong (Eds.), Handbook of school violence and school safety: From research to practice (pp. 413-427). Mahwah, NJ: Erlbaum.

Sugai, G., \& Horner, R. (2002). The evolution of discipline practices: School-wide positive behavior supports. Child \& Family Behavior Therapy, 24(1-2), 23-50.

Sugai, G., \& Horner, R. H. (2006). A promising approach for expanding and sustaining schoolwide positive behavior support. School Psychology Review, 35(2), 245-259.

Sugai, G., Horner, R. H., Dunlap, G., Hieneman, M., Lewis, T. J., Nelson, C. M., \& Ruef, M. (2000). Applying positive behavior support and functional behavioral assessment in schools. Journal of Positive Behavior Interventions, 2(3), 131-143.

Sugai, G., Horner, R. H., Algozzine, R., Barrett, S., Lewis, T., Anderson, C., \& Simonsen, B. (2010). School-wide positive behavior support: Implementers' blueprint and selfassessment. Eugene, OR: University of Oregon.

Todd, A. W., Campbell, A. L., Meyer, G. G., \& Horner, R. H. (2008). The effects of a targeted intervention to reduce problem behaviors elementary school implementation of check incheck out. Journal of Positive Behavior Interventions, 10(1), 46-55.

U.S. Department of Education, Office of Special Education Programs. (2005). Technical Assistance Center on Positive Behavioral Interventions and Supports: Final report. Washington, DC: Author.

Waasdorp, T. E., Bradshaw, C. P., \& Leaf, P. J. (2012). The impact of schoolwide positive behavioral interventions and supports on bullying and peer rejection: A randomized controlled effectiveness trial. Archives of Pediatrics \& Adolescent Medicine, 166(2), 149-156.

Walker, B., Cheney, D., Stage, S., Blum, C., \& Horner, R. H. (2005). Schoolwide screening and positive behavior supports: Identifying and supporting students at risk for school failure. Journal of Positive Behavior Interventions, 7(4), 194-204. 